\title{
Portraying gender in external marketing communication, using the example of a fair fashion label [version 1; peer
} review: 2 approved]

\author{
Juliane Lohmann, Marina Schmitz (D), Silvia Damme
}

CBS International Business School, Cologne, NRW, 50677, Germany

V1 First published: 20 May 2021, 3:8

https://doi.org/10.35241/emeraldopenres.14090.1

Latest published: 20 May 2021, 3:8

https://doi.org/10.35241/emeraldopenres.14090.1

\section{Abstract}

The topics of gender and sustainability are firmly anchored within a social discourse. Based on both factors, customers are placing demands on companies and have specific ideas on how they should be represented in advertising. The case study presented herein combines these two topics and examines the portrayal of gender in the external marketing communication of the fair fashion label ARMEDANGELS. By analysing individual Instagram publications, the case study identifies how the topic is generally portrayed on the company's channel. Furthermore, the perspectives of customers are determined through conducted interviews. When comparing the two sides, it becomes apparent that customers mostly approve of the attempt to break with conservative gender roles as well as an equal representation of the male and female personas. In addition to expanding the theoretical considerations of the triple bottom line as well as the S-O-R model, we derive recommendations for ARMEDANGELS and for other companies in the fashion industry. For customer retention purposes, companies should therefore focus on aligning the sexes, breaking with the general gender binary and integrating LGBTQ+ communities in future marketing measures.

\section{Keywords}

Gender, Marketing, Diversity, LGBTQ+, Fair Fashion, Sustainability

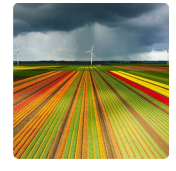

This article is included in the Responsible Management gateway.

\section{Open Peer Review \\ Approval Status \\ 1 \\ 2 \\ version 1 \\ 20 May 2021
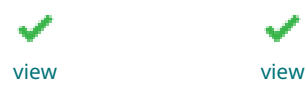 \\ 1. Noha El-Bassiouny (iD), German University in Cairo, New Cairo, Egypt \\ 2. Miguel Cordova (iD), Pontifical Catholic University of Peru, Lima, Peru \\ Any reports and responses or comments on the article can be found at the end of the article.}


Corresponding author: Marina Schmitz (m.schmitz@cbs.de)

Author roles: Lohmann J: Conceptualization, Data Curation, Formal Analysis, Investigation, Methodology, Visualization, Writing Original Draft Preparation; Schmitz M: Conceptualization, Funding Acquisition, Supervision, Writing - Review \& Editing; Damme S: Writing - Review \& Editing

Competing interests: No competing interests were disclosed.

Grant information: This work was supported by the European Commission (ERASMUS+ KA2 Strategic Partner-ship, 2018-1-HU01-KA202047730, ISSUE - Innovative Solutions for SUstainability in Edu-cation). The European Commission's support for the adaptation of this publication does not constitute endorsement of the contents which reflects the views only of the authors, and the Commission cannot be held responsible for any use which may be made of the information contained therein.

The funders had no role in study design, data collection and analysis, decision to publish, or preparation of the manuscript.

Copyright: (c) 2021 Lohmann J et al. This is an open access article distributed under the terms of the Creative Commons Attribution License, which permits unrestricted use, distribution, and reproduction in any medium, provided the original work is properly cited.

How to cite this article: Lohmann J, Schmitz $\mathrm{M}$ and Damme S. Portraying gender in external marketing communication, using the example of a fair fashion label [version 1; peer review: 2 approved] Emerald Open Research 2021, 3:8 https://doi.org/10.35241/emeraldopenres.14090.1

First published: 20 May 2021, 3:8 https://doi.org/10.35241/emeraldopenres.14090.1 


\section{Introduction}

The year 2018 is described as "the tipping point of all things gender" (Dobscha, 2019, p. 1). Humorous, sarcastic, challenging and enlightening perspectives are becoming louder, showing "how role models and feelings of shame manifest themselves, how they limit us - and that we can get rid of them" (Stokowski, 2016, blurb). They describe "existing discrimination mechanisms directed against transgender people" (Ewert, 2018, blurb) or discuss "sexism, feminism, equal opportunities and the women's quota" with influential men in Germany (Passmann, 2019, blurb). Four decades after the women's movement of the 1970s, women are now walking ambitiously and confidently through institutions, leaving many men behind. Society is changing, the gender roles are converging more and more whilst companies must adapt to this change (Baig, 2015, p. 84).

Students have been calling for politicians and businesses to address the effects of climate change and commit themselves to sustainable action as part of the Fridays for Future movement. The topic of sustainability is becoming a focus of society, and guidebooks which reflect on general consumption, provide instructions on DIY or instruct on how to be more conscious within the personal wardrobe are becoming increasingly popular (Schertl, 2020; van de Pol, 2020).

These developments make it clear that both components (gender and sustainability) are of particular relevance to the business perspective. This investigation of advertising combines both topics, setting its focus on the gender perspective, using a sustainable fashion company, and elaborates on the question as to what the duty of advertising ought to be, whether companies take on this task and to what extent customers are involved in decision processes. As a case study, we examine the company ARMEDANGELS and its marketing measures taken on the social media channel Instagram. The aim is to find out what strategy the company is pursuing with regard to the representation of gender. To this end, a content analysis will evaluate how ARMEDANGELS presents this on its channel. In addition, focused interviews will be used to find out how the label's customers perceive the corresponding portrayal, and what they expect from advertising.

The remainder of this article is structured as follows. After the theoretical underpinning is explained, which involves examining the triple bottom line of a company and the stimulus-organism-response model to explain customer behaviour, we thereafter provide an overview of the state of research in relevant areas such as gender in marketing, social media and slow fashion. This is followed by the methodology and qualitative approach of the study. The data analysis is based on Instagram publications by ARMEDANGELS from the period under review, supported by ten interviews with customers. Theoretical and practical implications are discussed and derived, and finally we provide an outlook on future research.

\section{Theoretical underpinning and literature review}

The stimulus-response model (S-R), and its later incarnation the stimulus (organism) response (S-O-R) model, emerged from the research field of behaviourism. In this model, it is assumed that an external stimulus is followed by learned or innate behaviour (a reaction) (Schneider et al., 2014). The basic S-R model originates from the field of consumer psychology and is one of the central and traditional models of advertising effectiveness: "The basic idea here was that consumer behaviour depends on certain stimuli and that behaviour can be explained and predicted once it is understood on which stimuli it depends" (Felser, 2015, p. 9). However, in this model, all processes taking place between stimulus and reaction happen in a 'black box' and are thus unknown. As a result, only one observable stimulus is considered for the investigation and interpretation of (consumer) behaviour, but no other psychological processes are taken into consideration. It is evident, however, that despite presenting the same stimulus to different people, the same reaction does not follow. Thus, the stimulus alone cannot be used to explain behaviour.

The organism absorbs these intervening factors in the extended neo-behavioural S-O-R model (Felser, 2015), whereby the stimulus remains a stimulus from the environment, and the reaction also remains a specific behaviour triggered by the stimulus. Before this action, however, psychological processes take place that control and influence the individual outcome. The previous 'black box' thus becomes more transparent and can be explored further. The processes that take place and can be researched are highly individual and persona specific (Schneider et al., 2014).

As a result of the changes in consumption options, and driven by the Internet and globalisation, society is placing new demands on companies. In his triple bottom line approach (TBL), John Elkington (1994) describes this new sense of responsibility as the "awakening of society." The TBL is based on the fundamental pillars of sustainability and thus encompasses economic, social, and ecological aspects (Krummer, 2009). The concept therefore means that companies not only commit themselves to one (financial) bottom line but also develop social and environmental strategies, set goals, and integrate them into their corporate system. The fact that all three areas are given the same weighting and priority (Henry et al., 2019; Nufer \& Ellsässer, 2018) is underlined by the model's mostly circular representation, in which the three equally sized areas are interlinked and a sustainable corporate concept is created at their interface. It is precisely this concept that companies need to adapt and respect, as it is the wish of society and thus of potential customers. Ultimately, it is their support and purchasing power that can decide the future of companies (Elkington, 1994). For illustration purposes, the respective factors of our integrative model are shown in Figure 1.

Gender stereotyping in advertising. According to Eisend (2019), how advertisements are ultimately understood depends on the current understanding of gender roles in the (broader) population. Since this understanding is continuously changing, advertising should respond to these changes. It becomes particularly problematic when marketing managers do not adapt their strategies to social change, meaning that sexism in advertising is 


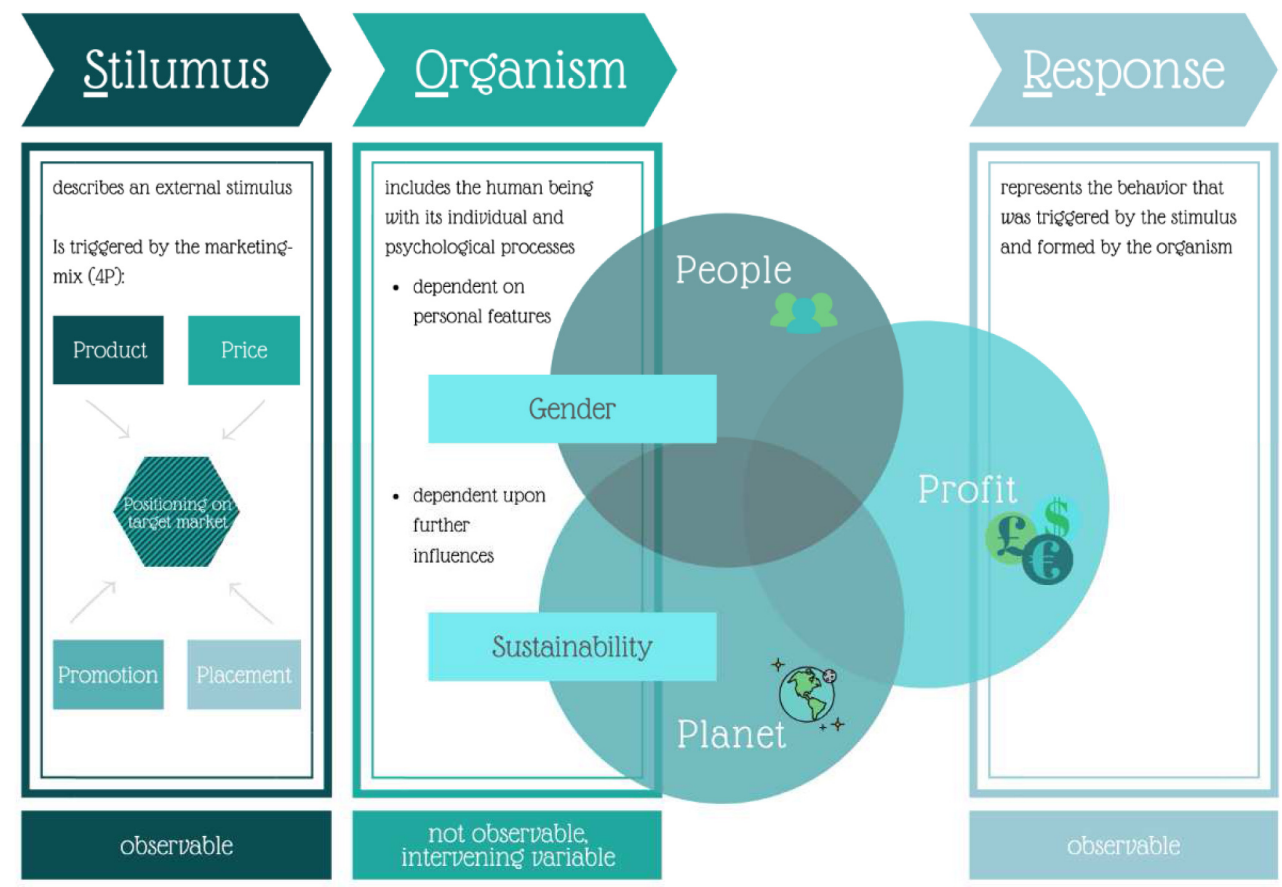

Figure 1. Integrative framework of the stimulus-organism response model and the triple bottom line.

primarily that which further increases social inequality. The Canadian sociologist Goffman (1976) created five categories in the 1990s to identify stereotyping advertisements. Today, these categories are still valid as characteristics of such advertising:

- $\quad$ Relative size (women are usually depicted smaller than men, take up less space and, in the case of film and television, have less speaking time)

- Lower rank (women have less decision-making power and work in subordinate positions, if at all)

- Feminine note/touch (women touch themselves or each other in an unnatural way to caress and thus present something)

- Ritualisation of dependence (posture, position and size signal subordination of the woman)

- Deliberate withdrawal (psychological withdrawal from a (social) situation; short attention spans and disorientation make women dependent on the protection of the man)

Gender marketing, diversity marketing, 'femvertising' and gay/LGBTQ+ marketing. Gender is utilized within various marketing strategies while each focuses on different interpretations of sex and gender. Gender marketing (GM) for one is based on biological differences and offers solutions for addressing the sexes as individual target groups. In general, GM suggests that men and women differ significantly in their buying behaviour (Jaffé \& Riedel, 2011). In contrast, Diversity Marketing discusses different characteristics of and individual differences between people (Neuß, 2008). Neuß (2008) distinguishes five potential diversity-categories:

- Visible differences (age, gender, origin)

- Demographic and socio-economic differences (income, education, ethnicity, nationality, occupation)

- Cultural and value-based differences (beliefs, value concepts, goals, understanding of roles, ways of thinking)

- Differences of any kind (today, there are no limits to these criteria)

Advertising that contains a reinforcing message for girls and women is known as 'femvertising', whereby women are specifically targeted, their womanhood is strengthened and their existence empowered (Drake, 2017). Herein lies the ambiguity of the matter - empowering messages that are simultaneously intended to encourage purchases and create brand loyalty (Sternadori \& Abitbol, 2019). The Dove campaign Real Beauty counts as a pioneer, with the year of its publication, 2004, viewed as the birth of femvertising (Feng et al., 2019).

Since the 1990s, homosexuality is no longer a taboo subject in Western society, and the LGBTQ+ community is recognised as a target group within marketing efforts (Gluckman \& Reed, 1997). On the one hand the emerged gay marketing includes 
the representation of gays and lesbians in communication concepts. On the other hand, it attempts to analyse consumer behaviour and develop relevant strategies within the target group. According to recent findings, the economy seems to have arrived in a gay-friendly market, but gay marketing is criticised for reducing an advertised target group to their sexual identity and neglecting other factors (Campbell, 2015). Thus LGBTQ+ marketing arose as it includes a broader target group with further orientations (Kuga, 2019). Family images and constellations are being redefined, and the LGBTQ+ community is being given more and more representation (Coffin et al., 2019; Witeck, 2014). Due to the (hitherto) low level of media coverage of people in the community, prejudices, myths and possibly fears, due to ignorance on the part of the majority of society, potentially prevail, but LGBTQ+ marketing could possibly break and neutralise this issue.

An overview of the different aspects in the described fields is provided below (Figure 2).

\section{Methods}

\section{Case study: ARMEDANGELS}

In the presented research context, a qualitative single-case study design has been chosen on the grounds that the research investigates a unique and specific phenomenon (Yin, 2014). The selected company ARMEDANGELS is one of the largest fair fashion firms in Europe. The Cologne-based company was founded in 2007 and sells fair and sustainably produced clothing in its online shop and in selected stationary sales outlets. Their products exclusively use fair and organic raw materials and textiles, they exclusively cooperate with Fairtrade certified partners and include complete sustainability throughout the entire value chain. In addition to ecological and sustainable standards, the company claims to focus on ethical raw material extraction, production and working conditions. In doing so, ARMEDANGELS pursues the philosophy of "timeless design instead of fast fashion, sustainable materials instead of cheap mass-produced goods and fair production instead of wage slavery. Everyone has a choice"2.

In addition to the analysis of Instagram publications, ARMEDANGELS customers were interviewed about their opinions on the portrayal of gender via the company's external marketing communications on Instagram, in order to formulate concrete demands on advertisers and to evaluate these portrayals. The main study revolves around 12 selected posts by ARMEDANGELS on Instagram.

\section{Data collection}

The data collection phase of the study stretched over the period from January to March 2020, beginning with a selection of Instagram posts and a listing of their key figures.

${ }^{2}$ Armedangels (2020). @ armedangels [Instagram Profile]. Retrieved 8 April, 2020 from https://www.instagram.com/armedangels/
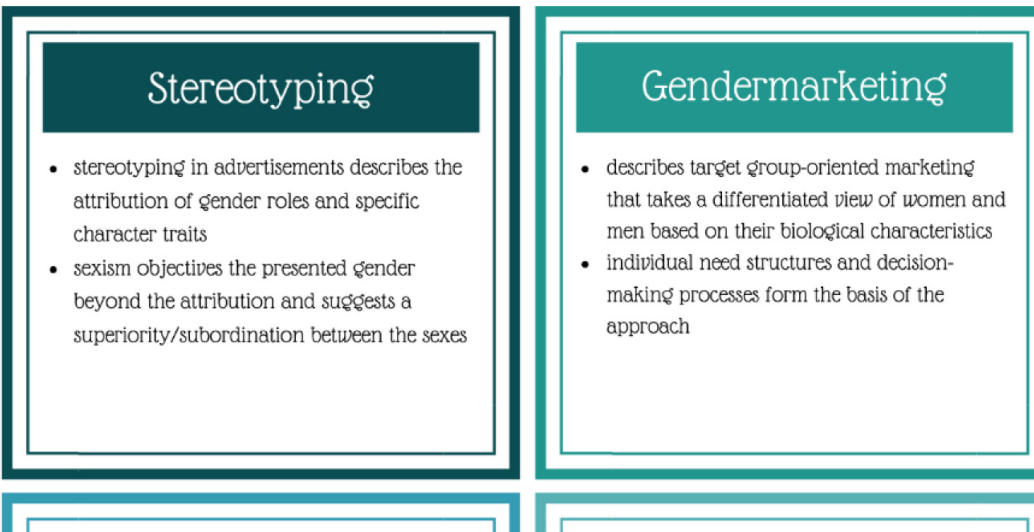

\section{Femvertising}

- Femvertising includes encourasing messaģes for oirls and women, whereby empowerment is strived for

- stereotypical representations are to be broken down and alternatives are to be offered that show possibilities and reassure chances

\section{Gay-Marketing}

- Gay-Marketinø describes an intensive analysis of a homosexual target oroup

- it goes beyond the mere representation of homosexuals in advertising, rather it aims to better understand consumer behavior and develop tarotet-oriented sales strategies

\section{Diversity-Marketinø}

- Diversity-Marketing derives from a globalizing world and wants to use the differences between business customers or consumers to its advantase

- it comprises a multitude of variables, which it tries to represent uniformly and equally in marketing measures

\section{LGBTQ+-Marketino}

- refines Gay-Marketing concepts to include further identities, identifications and orientations

Figure 2. Overview of research fields in gender marketing (own presentation). 
A period of six months was chosen for the study, in order to take into account seasonal changes and current campaigns. Accordingly, the time period was set from 1 July to 31 December 2019. These months include three seasons (summer, autumn and winter) as well as mid-seasons and special campaigns and promotions. After the period of time above was selected, posts, numbers of comments and likes were noted in a table (Appendix 1, Underlying data [Schmitz et al., 2021]) together with the photos, captions and hashtags.

Within the selected period ARMEDANGELS published a total of 186 posts that were compiled and examined. These were made up of 155 individual pictures, 12 posts with more than one picture and 19 videos. However, due to the increased complexity of the analysis and comparability, the evaluation was limited to the 155 individual images alone. A special focus for the interviews was set on 12 posts determined by the authors (Appendix 1, Underlying data, highlighted in yellow [Schmitz et al., 2021]) that represent a good cross-section of the entirety of the material.

Ten semi-structured interviews were conducted by the first author to check customer opinions and to assess ARMEDANGELS' advertising. In this regard, five males and five females were interviewed. Convenience sampling resulted in the first potential discussion partners from among the researcher's circle of acquaintances. To complement this sampling approach, a call for participation was shared on the first authors personal Instagram, and it was answered mainly by female contacts. Since the sample was to be enriched with additional male test persons, the researcher then contacted followers of the ARMEDANGELS Instagram channel at random. Of the 20 people contacted, four responded with interest. The interviews were conducted between 14 and 20 March 2020 and lasted between 20 and 45 minutes. The interview partners were in their $20 \mathrm{~s}$ and $30 \mathrm{~s}$, from different parts of Germany.

As part of the data collection process, verbal consent to the use of the data was obtained from all participants. Since all personal data in the case study was anonymised and is not traceable, written consent was not necessary. The oral consent was also recorded and included in the interview transcripts.

\section{Content analysis and coding}

Qualitative content analysis for evaluating the social media publications and conducted interviews following Mayring (2010), Diekmann (2010) and Mayring (2019) was chosen collectively among the authors within the presented research context. The category system and coding guidelines for Instagram contributions and customer interviews can be found in the Underlying data, in Appendix 2 and Appendix 4 (Schmitz et al., 2021).

Deductive coding of Instagram posts. Possible techniques for checking advertisements for stereotypes, such as those developed by McArthur \& Resko (1975) or Goffman (1976) can be applied in a highly modified form. For this reason, a combination of deductive and inductive categorisation was chosen for coding the data material, which will now be explained briefly.

For the 155 postings, six main categories were chosen for images and six categories for the corresponding captions. Category one (K1) indicates the type of posting. There are seven further subcategories (none, one, two, three or more than three people, as well as several pictures and videos). Since mainly pictures with people are of interest for evaluation, further categories refer exclusively to these pictures. Category two (K2) assigns the depicted people to a presumed gender. Subcategories are female, male and unidentifiable (i.e., none of the above). K2 is suitable for filtering out a general distribution of depicted people. Depending on whether one of the categories is represented more often than another, conclusions are drawn.

Categories three (K3) and four (K4) are derived from analyses by Goffman (1976), who describes that direction of gaze (K3) and frame (K4) can make statements about gender stereotyping (here according to Schroeder \& Borgerson, 1998 for example). Goffman (1976) determined that women often do not look into the camera but instead look into the distance, or their head (as well as other body parts) is cut out of the picture. This suggests, among other things, mental absence, apathy, lack of intelligence and a lack of focus. Accordingly, no head, looking away from and into the camera form the subcategories to K3. Whole body, upper body, legs, portrait, detail or otherwise form the subcategories of K4.

Body shape (K5) is intended to provide information about a diverse representation of body images. Here, the subcategories small, medium and large are formed. Finally, category six (K6) is an indicator of sexist advertising. Clothing (K6) is intended to filter out when people are not fully dressed, with the subcategories top, bottom and outfit. In combination with other categories, it can then be established which gender is more often shown (not) fully dressed. Categories K2-K6 also include the subcategory no information, which is used if no individual is shown in the respective picture.

Captions belonging to the pictures examined were analysed with the categories product info (K7), promotion (K8), addressing

\footnotetext{
3 In the early days of dealing with the (stereotypical) representation of the sexes in advertising, McArthur \& Resko (1975) and Goffman (1976) developed analytical methods and coding systems to filter out stereotypical advertising. Over the years, these were applied by researchers all over the world (Zawisza-Riley, 2019), which ensured the continuity and comparability of research. In the meantime, however, these models no longer keep pace with a changed advertising world and new technical advertising media. Especially in the area of non-binary, there are no coding systems or categories that allow for such research.
} 
the viewer (K9), call to action (K10), concrete gender reference (K11) and other text (K12). K7 was supplemented by the categories name, material and colour/fit. Further subcategories were deliberately not chosen here, as the focus should be on the individuals represented. Furthermore, caption categories could only be coded with the answer options Yes and No. Analysis of the captions for the Instagram contributions should be purely quantitative and represent a trend-setting indicator.

Inductive coding of customer interviews. For the coding of the customer interviews the authors chose an inductive approach to from categories from the interviews themselves. Category one (KI) describes the task and responsibility of advertising. How interview partners currently perceive advertising (KI.1 What is advertising like?), how they wish advertising to be (KI.2 What should advertising be like?) and where they see a concrete responsibility of advertising (KI.3) should be investigated. These findings can be used to examine to what extent the example of ARMEDANGELS already meets these requirements, or to derive measures on which advertisers should focus on the interests of their customers. Category two (KII Integration in the decision-making process) works out whether customers want to be included in a decision-making process.

Category three (KIII) comprises a general assessment of the topic of gender in the fashion industry. The aim is to assess the extent to which customers see the topic represented in the fashion industry and how relevant it should be. This category is based on the interview guidelines. Category four (KIV Examples) provides an indicator, depending on whether customers find it easy to give positive or negative examples of advertising, as to how much well or badly implemented advertising (from a gender perspective) is remembered.

In category five (KV ARMEDANGELS), all relevant information about the relationship between the interviewed customers and ARMEDANGELS is recorded. Category six (KVI) then refers back to the Instagram publications (meaning the 12 selected publications) of ARMEDANGELS that were used in the interview. It is subdivided into the subcategories impression/ conspicuousness (KVI.1), gender reference (KVI.2), evaluation (KVI.3) and concrete images (KVI.4). Category KVI.4 is also subdivided into a further 12 subcategories (KVI.4.1-KVI.4.12) in order to be able to record statements on the individual images separately. Category seven (KVII Statement in the context of gender) concludes with a summary of statements on the need for a public statement by companies with regard to gender issues.

The respective interviews have been conducted after assuring participants that their data will be treated confidentially. Additionally, the illustrations included in the underlying data are a reprint of the publicly available Instagram posts shared by ARMEDANGELS on their respective account.

\section{Results}

Analysis of Instagram posts

We now describe the evaluation of the Instagram posts, which is done in two steps. First, the contributions' images are evaluated, before the captions are considered more closely. In total, 155 contributions remain to be evaluated. Among them are 49 posts, which do not contain any people. Here, for example, landscapes (Image 4), objects (Image 11), rooms (Image 27), plants (Image 32), text on a plain background (Image 36), and others are shown. The other 106 contributions show photos with individuals, which are the main focus of the present analysis. On average, the selected contributions have 1,191 likes and 20 comments.

Analysis of the images. As 106 of the respective contributions evaluated include people, this means that almost $70 \%$ of the publications include people. Of these, one individual is shown in 81 pictures, two in 13 pictures, three in three and more than three people in nine contributions. These can be model photos (Image 55), situational photos (Image 45) or cooperation photos (Image 39). A total of 172 people are depicted, 101 of whom are female, 43 male and 28 not identifiable. Accordingly, in just under $60 \%$ of cases, the individual shown is female. Females are also more frequently represented in photos with only one individual (55 photos). Males in comparison are found in 17 out of a total of 81 photos with one individual, while the sex of the individual is not identifiable in nine postings. This may be due to the fact that the individuals are generally not identifiable, or they have androgynous features. The models (in pictures with only one individual) turn their gaze away from the camera or their head is not in the displayed image section on 35 occasions, while 46 people look directly into the camera. It can be noted that women look into the camera more often than unrecognisable individuals and men. The latter groupings look into the camera in an even distribution or instead avert their gaze.

If several people are depicted, it is usually a female and a male (eight out of 13 photos), sometimes two females (three photos), and twice the pairing is not visible. Reasons for this are cut off heads or the representation of the individual from behind. Males are not shown together. If there are more than two people (K2, subcategories, three people and more than three people), a mixture of the sexes is mostly shown. In $58.72 \%$ of the cases, the people depicted are shown with their whole body, and in $22.67 \%$ with their upper body. The remaining depictions show detailed shots of individual body parts or faces in the portrait, or the camera takes a perspective in which the individual is distorted.

Of the 172 people depicted (some appear several times), 166 $(96.51 \%)$ are wearing a complete outfit. In six cases, the model is wearing only a lower item of clothing, and in this regard it is noticeable that four of these individuals are female. The individuals shown almost exclusively wear a small dress size. In total, 136 of the 172 individuals are assigned to the subcategory small (K5). Overall, 11 individuals fall into the medium category, none under large and in 25 cases no assumption could be made about the body shape. The distribution within the sexes is similar. Female, male, androgynous or unidentified individuals are mainly small.

A first evaluation suggests that ARMEDANGELS wants to address a largely female target group. They are presented in 
a minor or non-sexualised or stereotypical way; however, this would have to be examined more closely in an individual case analysis. Nevertheless, according to Goffman's (1976) parameters for stereotypical advertising, the females in ARMEDANGELS' Instagram contributions are usually depicted in a whole-body pose, and thus they are not degraded by cutting and trimming body parts, especially the head (here according to Schroeder \& Borgerson, 1998). Women portrayed alone also look directly into the camera, which is another factor used to classify whether or not advertising is stereotyping, according to Goffman (1976). However, how glances are directed in photographs in which more than one individual is seen must be analysed again. For the selected contributions presented in customer interviews (Appendix 1, Underlying data, highlighted in yellow [Schmitz et al., 2021]), it is evident that in pictures 25 and 43, both people look directly into the camera, while groups in pictures 86 and 180 avert their gaze. However, this is due to the fact that on the one hand they are dancing (Image 86), and thus all are in motion, or on the other hand they turn their backs to the camera (Image 180).

Furthermore, females and males are depicted in similar clothing (Image 43 or 173), whereby ARMEDANGELS emphasises its credo "for every wardrobe" (Image 43) and does not promote any differences between the sexes. It is striking, however, that the majority of the models wear a (very) small dress size and have a narrow body shape. On this point, the company does not show any diversity whatsoever and does not represent the cross-section of society in the way diversity marketing approaches, for example, would wish. The company actively breaks gender norms in Image 25, both in its visual language and in the caption (which will be taken up again later). Here, the male individual wears a skirt and braids, the female a dress shirt and short hair. Both attributes are stereotypically assigned to the opposite sex.

Finally, this first insight into the depiction habits of ARMEDANGELS leads to the conclusion that, apart from the body shape of the models, they show a diverse picture of the sexes; furthermore, they play with androgyny and challenge viewers to question 'the system' (Image 36). In an explicit way, they dedicate themselves to the topic of gender in a contribution (Image 25) from the period under investigation. The extent to which individual images are nevertheless stereotypical in their representation remains to be examined in each individual case.

Caption analysis. All 155 contributions in the reduced sample were used as a basis for analysing the captions. Pictures with and without people were considered and their captions evaluated. Of these, $45.16 \%$ (70 captions) contain the name of the product presented, and $21.29 \%$ (33 captions) also mention the material of the garments presented. In almost two-thirds of the publications, the viewer is addressed, and in almost half of them, the viewer is asked to take part in a certain action. Examples in this regard include the request to find a product on the company's online shop (Image 116), to use clothing to express one's personality (Image 117) or to look up information on the company's website (Image 118). Frequently (in 80 of 155 contributions), other topics are also covered. These include, for example, environmental pollution (Image 62), snapshots (Image 64) or the day of the week and the season (Image 68). In one post (Image 25), the topic of gender is specifically addressed, and an opinion is articulated.

With regard to gender in marketing, the statements in the captions are not very concrete from a superficial overview. According to Lindner (2004), for example, product information or technical details are rarely given when females are shown in pictures, but they are more likely to be listed in male-oriented advertising. To what extent this applies to ARMEDANGELS' advertising will have to be investigated in a future study. In connection with the large representation of females in their Instagram contributions, and the regular mentioning of product names or materials, it can be assumed that in this case no differentiation between the sexes is made. The topic of gender thus becomes relevant in connection with the captions in one contribution. In picture 25 of the sample, ARMEDANGELS explicitly calls for people to wear what they want to wear, and in doing so, consumers should not be restricted by gender norms or by the opinions of others, and they should also openly express their views. Through these statements, the company takes a solid stand with regard to gender issues and tries to convey that there are no gender limits to its products. Further captions can also be used to refer to the topic of gender in a broader sense. Captions to Image 46 and Image 180, for example, declare "Do what you like - wear what you want" (Image 46) and "Whoever you are and whatever you believe, love is a concept we can all get behind. Join us in saluting every kind of love. Love yourself, love your sister, love your planet" (Image 180).

The call in Image 46 is in a similar vein to Image 25 , but the message of Contribution 180 aims at the general acceptance of each individual. The acceptance of all genders, forms of expression or dress styles could be included here. Such an interpretation is left to the observer.

\section{Analysis of the customer interviews}

Each of the ten interviews was transcribed, in order to analyse the customer perspective on advertising in general and on ARMEDANGELS' Instagram publications in particular. The transcribed interviews can be found in the Extended data while the interview guideline can be seen in the Underlying data, in Appendix 3 (Schmitz et al., 2021).

Representation of gender in the advertising of ARMEDANGELS. The interview partners describe ARMEDANGELS' Instagram publications as "clean," "unagitated," "modern," "artistic," "uniform," "reserved" and "aesthetic" compared to those of other fashion companies (I1, I3, I6). They recognise diversity in the models in terms of a balanced presentation of female and male individuals, skin colours, hairstyles, ethnicities and different characters (I2, I5, I8). According to the interviewees, it is also noticeable that the posts often play with the fact that the sex of the individual depicted cannot be identified 
or that pictures are cropped to achieve this effect (I1, I7, I8). Among others, picture 17 is mentioned. At a cursory glance, it is not possible to tell whether the individual is male or female; it is only the precise examination of the image and the individual itself, rather than the item of clothing in focus, that reveals the model's feminine features (I1, I8). I10 finds this a very pleasant representation, because a gender aspect is not in focus. Even if a closer look might lead to the assumption that the product should appeal to women, at the same time, men are not excluded by the presentation (I1, I10). Image 80 is similarly designed, according to I6. Although a female is depicted here, the interviewee notes that it could be an androgynous woman or a feminine man. The model's discreetly chosen make-up also directs the focus more onto the product (I1). For I8, this also supports the message in the caption, which states that the product is for men and women, regardless of the sex of the individual shown. Accordingly, depicted people do not distract from the product being advertised, which means that it is the sole focus of attention. For this reason, some interviewees describe the Instagram contributions as neutral representations of people (I10), with little attention paid to physicality (I9) and sexless clothing (I6). Images 43 and 173 are especially emphasised in this context. By dressing in similar garments, colours or cuts, no difference is made between the individuals (I2, I8, I9). Rather, in picture 173, supposed roles are swapped for clothing. I 2 describes that a reversal of norms has taken place through the tight clothing of the male and the wide fit clothing of the female. Only I5 feels that the representation in the picture mentioned is classical. Since a woman and a man are shown kissing, a traditional portrayal of the sexes in the eyes of I5.

Despite a more diverse representation of model types and a gender-neutral presentation of the clothing, I6 and I7 criticise the fact that no difference is shown in the body shape of the individuals. In contrast to I1, they feel a lack of representation in terms of societal reality. They also criticise a partly clichéd depiction of men and women, although opinions are divided on this point in the images used. I6 and I10, for example, take the view that although picture 74 shows the buttocks of a presumably female individual, the focus is nevertheless on the product itself. I8 and I9 are of the opposite opinion, in that they think the choice of image detail in combination with the sex of the model should be reconsidered. They see the body part and not the advertised product in focus, thus sexualising the model. Images 109 and 173 also split the views on stereotypical gender representation. On the one hand, image 109 is described as aesthetically pleasing by I2, as it advertises pollutant-free jeans with a well-thought-out and witty caption. I7, on the other hand, argues that here the depiction of a muscular topless male body sexualises the man. I7 further questions why a $\mathrm{PoC}^{4}$ model was chosen in such a context. It is interesting to note that female interviewees, in particular, give some thought to a sexualised portrayal, while male interviewees question the pose of the model (I8) but describe the image as not

\footnotetext{
${ }^{4} \mathrm{PoC}=$ people/person of color. Describes people who do not have a White skin color and does not try to put any further value into the description.
}

disturbing and aesthetic (I10). In Image 133, the arguments are formulated in a similar direction. The contribution shows a female who looks seductively into the camera while pulling up her white T-shirt and putting it in her mouth. Again, opinions vary from an attractive and appealing portrayal (I1, I2), to a focus on the woman and her femininity (I5, I9).

Nevertheless, the overall impression of the representation of the sexes is described as "gender-neutral" and "multicultural" (I1, I3). Interviewees advocate that the company openly and recognisably reflects on how people are portrayed and how the sexes are represented (I9, I2). I2 describes a successful alternation between explicit addressing and implicit allusions. For example, Image 2 obviously breaks gender norms and sends the message that everyone should wear what he or she wants (I4), while Image 180 sends a subliminal message (I8). Image 59 is also particularly well-realised for I3 in this respect. The way in which the male individual is staged in the picture, and the product described in the caption, therefore speaks for a feminine individual from the perspective of picture composition. Although men are still rarely staged in this way, according to I3, the picture breaks gender norms in a pleasant way and also allows men to be "soft and breathable" (Image 59).

Evaluation of the representation of gender in ARMEDANGELS' advertising. ARMEDANGELS' advertising appeals to the interviewees in this context above all, because it sets itself apart from other fashion companies and does not attempt to reflect a distorted image of society (I1, I5). In addition, it tries to break gender norms, shows diversity and focuses more on the products than on the sexes of the people portrayed (I3, I4, I10). Interviewees particularly advocate a humorous and at the same time profound approach to the issue of breaking up (gender) norms through reverse stereotypes or representations of males and females (I3, I7). While of course not all pictures appeal to everyone (for example, picture 180 is too exaggerated and deliberately depicted for I1, whilst I8 cannot identify with picture 173), the interview partners describe an overall consensus that ARMEDANGELS' Instagram appearance is progressive (I2, I6) and "takes steps in the right direction by [...] showing diversity and $[\ldots]$ thinking about gender roles [...] they make a first reflected impression" (I9). By communicating their values and opinions on political issues, they align themselves with those of their desired target group (I6, I10), although it is difficult to satisfy all views (I9), a stronger focus on LGBTQ+ communities and gender identities are desired (I6).

\section{Discussion and conclusions}

The evaluation of the Instagram contributions shows that ARMEDANGELS does not focus on gender marketing as such, but it does try to pursue a diversity approach that includes and seeks to address LGBTQ+ communities. The company tries to break away from stereotyping and focuses on empowering messages and gender equality.

A largely homogeneous opinion can be derived from the interviews conducted with customers. Most of the interviewees recognise ARMEDANGELS' advertising as progressive, but they 
especially emphasise the balanced representation of females and males, as well as the presentation of diversity and the attempt to actively break with gender norms. The assumption that the company under investigation implicitly takes a position on the subject of gender in pictures and their captions is also confirmed. It is noteworthy that the tendency described above, i.e. to portray people in a more androgynous or gender-neutral way, is supported by the demands of the interviewees and is seen as positive. Nevertheless, some individual images were criticised in the interviews and perceived as stereotyping. It is appreciated that ARMEDANGELS does not impose their message, but it nevertheless has a strong and partly subconscious effect. It is interesting to note that the diverse depictions of cultures, ethnicities and skin colours are often not placed in the gender context. Contrary to the principle described above, diversity is related to externalities, while gender identities, gender identification and other orientations represent a separate, more specific context.

In particular, the lack of clarity about the function of advertising can be answered by the findings obtained herein. The question focuses on the extent to which advertising should hold up a proverbial mirror to society, or if values and behaviours should be influenced and shaped by it. The interviewees in the present study clearly wish that advertising would use its reach and presence to soften traditional values and attitudes as well as break with societal norms. By associating advertising as much as possible with social normality, it should raise awareness of gender diversity through its representation. According to the interviewees, ARMEDANGELS' communication is moving in a corresponding direction, actively encouraging consumers to manifest personal attitudes and values with the greatest possible openness and acceptance of all people.

\section{Theoretical and practical implications}

The S-O-R model, which attempts to understand the mechanisms behind a consumer's purchase decision, still works within a grey area that is difficult to grasp, i.e. the psychological and individual processes that motivate a person to act. Based on the findings of the present study, it can be assumed that the gender component influences decision-making processes. The stimulus is triggered by measures in the marketing mix, whilst the organism, as a psychological process, is dependent on personal characteristics and other influences, including the representation of gender and breaking with gender norms. According to the triple bottom line theory, gender can be assigned to social responsibility and ecological responsibility when we consider the overconsumption of fashion items, for example. The economic component of TBL covers the reaction of customers, insofar as this is presented as a purchasing decision.

ARMEDANGELS customers recognise the successful staging of diversity and the desire to break with gender norms in a partly humorous and partly appealing way. The selected customers advocate the gender-neutral representation of females and males, as well as the transfer of such a message to the brand's clothing. In this way, they suspect that the company has already given thought to the strategic representation of gender, which, according to them, is an elementary part of strategy development for fashion companies. An open, political position in relation to this and other factors is considered praiseworthy and exemplary as well, and they acknowledge that ARMEDANGELS uses its position and reach to speak out and form opinions on a socially sensitive topic.

Nonetheless, discussion partners see further possibilities for improvement. They hope that current strategies will be expanded, and different communities will be addressed more often. Another point of critique is the lack of representation of real body images. Marketing communication on Instagram should incorporate values demonstrating a good fit between the corporation and its customers. In addition, ARMEDANGELS could work more with androgynous models and make it clear through the captions that a gender-specific assignment is relevant neither for the shown individual nor for their clothing. An even more diverse portrayal of people could be achieved by representing different body shapes and sizes, people wearing headscarves or people with physical disabilities, with the former in particular reflecting the majority demands of customers.

The values shared by customers and companies alike lead to the assumption that brand loyalty and willingness to buy might continue to be increasingly interlinked. Stereotypical approaches, as well as elements in gender marketing, seem to be very outdated and no longer meet social changes in a target-oriented way. In today's world, companies are increasingly seen as having a responsibility that is linked to their position, size, power and (potential) influence. In terms of (strategic) decision-making, companies should take into account the competencies, skills and values of society and align measures precisely. This does not require the active integration of consumers, merely a thorough analysis of the relevant factors. Due to the daily flood of advertisements and the increasingly less conscious perception of them, dialogue partners want a more concrete and targeted orientation to fit their needs. Companies should therefore make a point of knowing their target group exactly, following the parameters described above. Moreover, they should not conceal any facts, functions or information, or make their ads susceptible to misinterpretation; instead, they should communicate honestly and clearly and reflect their contribution within society. An awareness of the far-reaching effects of advertising is thus required. In the eyes of customers, companies remain - first and foremost - manufacturing and marketing institutions. However, in order to stand out from the market, and to engage with customers in a brand-binding manner, a company needs to position itself through its means of communication and stand by its brand in order to satisfy the (moral) values and attitudes with which customers identify.

\section{Limitations and avenues for future research}

There are some limitations to this study. First is the limited number of interview participants, who were also rather demographically homogeneous. A comparison with other age groups is therefore necessary to verify the respective results. Second, new parameters should be set in the field of gender stereotyping regarding what 'stereotyping' actually means and 
how an investigation could be adapted to today's technical possibilities across marketing channels. Third, as communication runs both ways, a complementary investigation of ARMEDANGELS' experts, e.g. heads of corporate responsibility, social media or diversity management, would be useful. In addition, a quantitative study, which obtains customer opinions on Instagram publications from a representative sample, would reveal whether and to what extent initial findings and indicators can be refuted, confirmed or expanded.

In summary, it should be noted that the topic of gender in marketing is a particularly interesting and relevant field of research for the future, and it thus calls for a new and more open focus. It would be interesting, therefore, to investigate this respective topic from a longitudinal perspective. Furthermore, an international comparison would produce further insights into cross-cultural and societal differences in regard to the perception of gender stereotypes and gender roles in fashion marketing.

\section{Data availability}

\section{Underlying data}

OSF: Portraying gender in external marketing communication, using the example of a fair fashion label. https://doi.org/10.17605/ OSF.IO/DF4MJ (Schmitz et al., 2021)

This project contains the following underlying data:

- Underlying Data - Appendix 1 Overview of all Instagram postings.xlsx

- Underlying Data - Appendix 2 Category system and coding guideline for Instagram postings.pdf

- Underlying Data - Appendix 3 Interview guideline for customer interviews.pdf

- Underlying Data - Appendix 4 Category system and coding guideline for customer interviews.pdf

\section{Extended data}

OSF: Portraying gender in external marketing communication, using the example of a fair fashion label. https://doi.org/10.17605/ OSF.IO/DF4MJ (Schmitz et al., 2021)

This project contains the following extended data:

- Extended Data 1 - Coded Instagram Posts (German).pdf

- Extended Data 2 - Transcription Guideline.pdf

- Extended Data 3 - Transcribed Interviews.pdf

- Extended Data 4 - Coded Interviews.pdf

Data are available under the terms of the Creative Commons Zero "No rights reserved" data waiver (CCO 1.0 Public domain dedication).

\section{Disclaimer}

At this point, it is important to remark that the present appendixes (as well as the Extended data) have been translated from German into English as part of the present publication. In this context, the individual appendixes (and Extended data) have been translated separately from one another, so that there may be discrepancies between them. This may occur, for example, in the case of the anchor examples (comparing Appendix 2 and 4 to the Extended data 3 ). These translation discrepancies, however, will correspond in the general meaning of the statement or example.

\section{Acknowledgements}

This research paper presents a shortened and translated version of the master thesis written by the first author. Only the adapted version is supported by the European Commission as indicated in the section "grant information".
Armedangels: @armedangels [Instagram profile]. 2020; Retrieved 08. April 2020.

Reference Source

Baig U: Gender Marketing. Handlungsempfehlungen für ein erfolgreiches geschlechterspezifisches Marketing [Gender Marketing. Recommendations for successful gender specific marketing]. Hamburg: Diplomica Verlag GmbH. 2015.

Campbell JE: Gay and Lesbian / Queer Markets / Marketing. In: D. T. Cook \& J. M. Ryan (Hrsg.). The Wiley Blackwell Encyclopaedia of Consumption and Consumer Studies. Oxford: John Wiley \& Sons, Ltd. 2015.

Publisher Full Text

Coffin J, Eichert CA, Nolke AI: Towards (and beyond) LGBTQ+ studies in marketing and consumer research. In: S. Dobscha (Hrsg.). Handbook of Research on Gender and Marketing. Cheltenham \& Northampton: Edward Elgar Publishing. 2019; 273-293.

Publisher Full Text

Diekmann A: Empirische Sozialforschung. Grundlagen, Methoden, Anwendungen [Empirical Social Research. Fundamentals, methods, applications]. (4th ed.). Reinbeck nahe Hamburg: Rowohlt Taschenbuch Verlag. 2010.

Dobscha S: Introduction to the Handbook of Research on Gender and
Marketing. In: S. Dobscha (Hrsg.). Handbook of Research on Gender and Marketing. Cheltenham \& Northampton: Edward Elgar Publishing. 2019; 1-7. Publisher Full Text

Drake VE: The Impact of Female Empowerment in Advertising

(Femvertising). Journal of Research in Marketing. 2017; 7(3): 593-599.

Reference Source

Eisend M: Gender roles. J Advert. 2019; 48(1): 72-80.

Publisher Full Text

Elkington J: Towards the Sustainable Corporation: Win-Win-Win Business Strategies for Sustainable Development. Calif Manage Rev. 1994; 36(2): 90-100.

Publisher Full Text

Ewert F: Trans, Frau, Sein: Aspekte geschlechtlicher Marginalisierung [Trans Woman Being Aspects of Gender Marginalization]. Münster: edition assemblage. 2018.

Reference Source

Felser G: Werbe- und Konsumentenpsychologie [Advertising and consumer psychology]. (4th ed. \& fully revised edition). Berlin \& Heidelberg: SpringerVerlag. 2015.

Publisher Full Text

Feng Y, Chen H, He L: Consumer Responses to Femvertising: A Data-Mining 
Case of Dove's "Campaign for Real Beauty" on YouTube. J Advert. 2019; 48(3): 292-301.

Publisher Full Text

Gluckman A, Reed B: The Gay Marketing Moment. In: A. Gluckman \& B. Reed (Hrsg.). Homo economics: Capitalism, community, and lesbian and gay life. New York: Routledge. 1997; 3-10.

Reference Source

Goffman E: Gender Advertisements. London: Macmillan Publishers Limited. 1976

Publisher Full Text

Henry LA, Buyl T, Jansen RJG: Leading corporate sustainability: The role of top management team composition for triple bottom line performance. Business Strategy and the Environment. 2019; 28(1): 173-184.

Publisher Full Text

Jaffé D, Riedel S: Werbung für Adam und Eva: Zielgruppengerechte Ansprachedurch Gender Marketing Communication [Advertising for Adam and Eve. Addressing target groups through Gender Marketing Communication]. Weinheim: Wiley-VCH. 2011.

Reference Source

Krummer S: SWOT-gestützte Analyse des Konzepts der Corporate Social Responsibility: Die soziale und ökologische Verantwortung der Unternehmen [SWOT-supported analysis of the concept of Corporate Social Responsibility]. The social and ecological responsibility of companies. Kempten: Books on Demand GmbH. 2009; 140.

Reference Source

Kuga M: Marketing with Meaning. Queer Music Fans have always been loyal (and lucrative) customers. But to reach them, labels now have to look beyond the dancefloor. Billboard, 2019; 19: 52-53.

Lindner K: Images of Women in General Interest and Fashion Magazine Advertisements from 1955 to 2002. Sex Roles. 2004; 51(7/8): 409-421. Publisher Full Text

Mayring P: Qualitative Inhaltsanalyse. Grundlagen und Techniken. [Qualitative content analysis. Basics and techniques]. (11. act. \& revised edition). Weinheim and Basel: Beltz Verlag. 2010.

Reference Source

Mayring P: Qualitative Inhaltsanalyse [Qualitative content analysis]. In: U. Flick, E. von Kardorff, \& I. Steinke (eds.). Qualitative Research. A Manual (13th ed.,). Reinbeck near Hamburg: Rowohlt Taschenbuch Verlag. 2019; 468-474. McArthur LZ, Resko BG: The portrayal of men and women in American television commercials. The Journal of Social Psychology. 1975; 97(2): 209-220. Publisher Full Text

NeußJ: Wahrnehmung und Relevanz von Diversity. Im Hinblick auf ökonomischen Mehrwert, Markt- und Innovationserfolg [Perception and relevance of diversity. With regard to economic added value, market and innovation success]. [dissertation]. Berlin: Technische Universität Berlin.

2008.

Nufer G, Ellsässer L: Corporate Social Responsibility und Marketing

[Corporate Social Responsibility and Marketing]. Reutlinger

Diskussionsbeitrag, Nr. 2018-2. 2018.

Reference Source

Passmann S: Alte weisse Männer. Ein Schlichtungsversuch [Old white men. An attempt at conciliation]. Köln: Kiepenheuer \& Witsch. 2019.

Schertl M: Zero Waste. Do it yourself. Mit einfachen DIY-Projekten im Alltag Müll vermeiden und nachhaltig leben. [Zero Waste. Do it yourself. Avoiding waste in everyday life with simple DIY projects and living sustainably]. Stuttgart: frechverlag GmbH. 2020.

Schmitz M, Lohmann J, Damme S: Portraying gender in external marketing communication, using the example of a fair fashion label. 2021

http://www.doi.org/10.17605/OSF.IO/DF4M]

Schneider FM, Retzbach A, Barkela B, et al.: Psychologie der

Organisationskommunikation [Psychology of organizational

communication]. In: A. Zerfass \& M. Piwinger (eds.). Handbuch

Unternehmenskommunikation. Strategie, Management, Wertschöpfung [Corporate

Communications Handbook. Strategy, management, value creation] (2nd, fully

revised edition). Wiesbaden: Springer Gabler. 2014; 449-469.

Schroeder JE, Borgerson JL: Marketing images of gender: A visual analysis.

Consumption Markets \& Culture. 1998; 2(2): 161-201.

Publisher Full Text

Sternadori M, Abitbol A: Support for women's rights and feminist selfidentification as antecedents of attitude toward femvertising. J Consum Mark. 2019; 36(6): 740-750.

Publisher Full Text

Stokowski M: Untenrum frei [Free at the bottom]. Reinbeck nahe Hamburg: Rowohlt Taschenbuch Verlag. 2016.

van de Pol DE: Achtsam Anziehen. Mit 10-Wochen-Programm zum

nachhaltigen Kleiderschrank [Dress carefully. With a 10-week programme for a sustainable wardrobe]. München: Christian Verlag. 2020.

Reference Source

Witeck B: Cultural change in acceptance of LGBT people: Lessons from social marketing. Am J Orthopsychiatry. 2014; 84(1): 19-22.

PubMed Abstract | Publisher Full Text

Yin RK: Case Study Research. Design and Methods (5. Aufl.). London, New Delhi \& Singapur: SAGE Publications Inc. 2014.

Zawisza-Riley M: Advertising, Gender and Society: A Psychological Perspective. (1. Aufl.). Oxon \& New York: Routledge. 2019.

Publisher Full Text 


\section{Open Peer Review}

\section{Current Peer Review Status:}

\section{Version 1}

Reviewer Report 17 November 2021

https://doi.org/10.21956/emeraldopenres.15177.r27835

(C) 2021 Cordova M. This is an open access peer review report distributed under the terms of the Creative Commons Attribution License, which permits unrestricted use, distribution, and reproduction in any medium, provided the original work is properly cited.

\section{Miguel Cordova}

Pontifical Catholic University of Peru, Lima, Peru

Understanding consumer behavior is critical for firms in order for them to analyze and respond with proper business initiatives and market strategies. Moreover, relevant megatrends such as global risks, environmental concerns, and diversity management are impacting the way consumers evolve and decide, is urgent that firms could follow them through this evolution, keeping their pace and progressively fitting into their expectations. Companies that would not adapt themselves to these changes, besides a less competitive position in the market, would not be able to provide any value for society. Hence, this study approaches this important phenomenon from the marketing literature to explain how the focal firm, ARMEDANGELS, is responding to the diversity management expected by its consumers, through managing one of its main external communication channels, Instagram.

According to Georgiadou et al. (2019) ${ }^{1}$, companies have to include initiatives that are in line with their main vision, and including diversity management allows them to reach underrepresented groups while joining the expectations of these to the overall business strategy. In the case of ARMEDANGELS, it has not only integrated diversity management within its customers' strategy but also has combined the diversity perspective with what the company is pursuing. Hence, the article has achieved a proper integration of the marketing literature, and how diversity in this case leads the path towards sustainability achievement. One detail authors have missed, that could be extended in further research, is analyzing how marketing communication literature could be developed, by exploring some context's particularities. Following Georgiadou et al. (2019) ${ }^{1}$, diversity elements such as religion and culture may frame how organizations and people respond. Thus, location matters, and will be extremely beneficial for the literature in this field to elaborate some propositions from the results.

Another interesting element to discuss while adopting a diversity orientation is related to additional outcomes, such as reputation. The paper provides an overview of the benefits, which accomplish the proposed analysis for the case study. Nevertheless, what is developed by the authors suggests interesting additional questions for discussion. Does the implementation of a gender perspective increase sales or firms' reputation? or both? In which cases including 
contemporary concerns such as diversity or sustainability in the business strategy could improve operational results or corporate reputation? According to Gomez-Trujillo et al. (2020) ${ }^{2}$, most of the cases have evidenced that sustainable initiatives come before corporate reputation, just as ARMEDANGELS is doing, following the results of the analyzed study. Also, adding a sustainability approach into the business seems to fulfill stakeholders' expectations, providing the firm some sort of "social license" to operate.

Human stereotypes tend to anticipate how people must behave or even think. Traditionally, these constraints were strongly related only to gender differences between men and women, such as what economic activity they should prefer (Cordova and Huaman, 2019) ${ }^{3}$. However, global trends have emphasized the need to think of diversity management as more complex than that. This study based on ARMEDANGELS has demonstrated the prevalence of women in some organizational strategies, as well as the level of importance that new businesses are giving to them. Thus, companies that would be willing to adhere to sustainable practices within their operations would have to be ready to begin structural changes, aligning their initiatives with their visions, and also shift forward their strategy, in the very same direction of what their stakeholders expect they move to (Gonzalez-Perez et al., 2021). ${ }^{4}$

Finally, the study, besides allowing replicability, uses an adequate research method, since observing the phenomenon in detail would permit finding specific responses and behavioral patterns of ARMEDANGELS's consumers. The in-depth interviews can provide explanations for the content analysis of Instagram posts as well as their interactions. Moreover, the results of the study as well as the implications provided would reinforce how companies could promote, engage, and deploy sustainable initiatives, even though the more sensitive ones such as diversity and inclusion. The world is changing indeed, and every society's actor has to spin with it.

\section{References}

1. Georgiadou A, Gonzalez-Perez M, Olivas-Luján M: Diversity within Diversity Management: Where We Are, Where We Should Go, and How We Are Getting There. 21: 1-20 Publisher Full Text 2. Gomez-Trujillo A, Velez-Ocampo J, Gonzalez-Perez M: A literature review on the causality between sustainability and corporate reputation. Management of Environmental Quality: An International Journal. 2020; 31 (2): 406-430 Publisher Full Text

3. Córdova M, Huamán F: Absence of opportunities can enhance womens high-growth entrepreneurship: empirical evidence from Peru. 2019. 32-51 Publisher Full Text

4. Gonzalez-Perez M, Cordova M, Hermans M, Nava-Aguirre K, et al.: Crises conducting stakeholder salience: shifts in the evolution of private universities' governance in Latin America. Corporate Governance: The International Journal of Business in Society. 2021; 21 (6): 1194-1214 Publisher Full Text

Is the work clearly and accurately presented and does it cite the current literature? Yes

Is the study design appropriate and is the work technically sound?

Yes

Are sufficient details of methods and analysis provided to allow replication by others? Yes 
If applicable, is the statistical analysis and its interpretation appropriate?

Not applicable

Are all the source data underlying the results available to ensure full reproducibility? Yes

Are the conclusions drawn adequately supported by the results?

Yes

Is the argument information presented in such a way that it can be understood by a nonacademic audience?

Yes

Does the piece present solutions to actual real world challenges?

Yes

Is real-world evidence provided to support any conclusions made?

Yes

Could any solutions being offered be effectively implemented in practice?

Yes

Competing Interests: No competing interests were disclosed.

Reviewer Expertise: Sustainability, Sustainable Supply Chains, Corporate Governance, Power and Influence in Organizations, Entrepreneurship, International Business.

I confirm that I have read this submission and believe that I have an appropriate level of expertise to confirm that it is of an acceptable scientific standard.

Reviewer Report 24 June 2021

https://doi.org/10.21956/emeraldopenres.15177.r27577

(c) 2021 El-Bassiouny N. This is an open access peer review report distributed under the terms of the Creative Commons Attribution License, which permits unrestricted use, distribution, and reproduction in any medium, provided the original work is properly cited.

\section{Noha El-Bassiouny}

Faculty of Management, German University in Cairo, New Cairo, Egypt

The study at hand aims at analyzing the role of gender in the marketing communications (presented on Instagram) for a large and well-known sustainable company in Europe.

The study is well-grounded in the literature and well-executed. It is recommended, however, that the author(s) highlight more the contribution of the study (and the research gaps it fills) in both 
the marketing and the gender roles literature.

Furthermore, it is recommended to briefly draw on and relate the findings of the study to extant theories on gender representations in general (such as Social Role Theory). This would greatly enhance the work.

Finally, I would recommend that more rationalization for the choice of Instagram (as a social media) is presented - either through previous support from the literature on digital marketing or from practical statistics (e.g. that it is maybe the most used social medium in Europe?)

I would like to thank the author(s) for an interesting article!

Is the work clearly and accurately presented and does it cite the current literature?

Yes

Is the study design appropriate and is the work technically sound?

Yes

Are sufficient details of methods and analysis provided to allow replication by others? Yes

If applicable, is the statistical analysis and its interpretation appropriate?

Not applicable

Are all the source data underlying the results available to ensure full reproducibility? Yes

Are the conclusions drawn adequately supported by the results? Yes

Is the argument information presented in such a way that it can be understood by a nonacademic audience?

Yes

Does the piece present solutions to actual real world challenges?

Yes

Is real-world evidence provided to support any conclusions made?

Yes

Could any solutions being offered be effectively implemented in practice?

Yes

Competing Interests: No competing interests were disclosed.

Reviewer Expertise: Marketing 
I confirm that I have read this submission and believe that I have an appropriate level of expertise to confirm that it is of an acceptable scientific standard. 